\title{
Ease vs. noise: Long-run changes in the value of transport (dis)amenities*
}

\begin{abstract}
For a complete cost-benefit analysis of durable infrastructures, it is important to understand how the value of non-market goods such as transit time and environmental quality changes as incomes rise in the long-run. We use difference-in-differences and spatial differencing to estimate the land price capitalization effects of metro rail in Berlin, Germany today and a century ago. Over this period, the negative implicit hedonic price of rail noise tripled. Our results imply income elasticities of the value of noise reduction and transport access of 2.2 and 1.4, substantially exceeding cross-sectional contingent valuation estimates.

Keywords: Accessibility, spatial differencing, noise, difference-in-differences, income elasticity, land price Version: June, 2019

JEL: R12, R14, R41, N73, N74
\end{abstract}

Conflict of interest and financial disclosure statement

The authors declare that they have no conflict of interest and no material financial interests that relate to the research described in the above paper. All sources of funding are disclosed below.

- London School of Economics and Political Sciences (LSE) \& Centre for Economic Policy Research (CEPR). g.ahlfeldt@lse.ac.uk,www.ahlfeldt.com

$\otimes$ Darmstadt University of Technology. nitsch@vwl.tu-darmstadt.de

- Touro College Berlin. wendland@urbancontext.org

* We thank the editor Roger von Haefen, two anonymous reviewers, seminar and conference participants in Berlin (Humboldt), Bristol (RES), Barcelona (UEA), Copenhagen (UEA), Heidelberg, Miami (UEA), München (Ifo), Orléans, Toulouse (SEA), Vaduz (VfS), Venice (CESIfo), Würzburg, and Zurich (KOF) and especially Thilo Albers, Maximilian von Ehrlich, Gustaf Engsström, Stephan Heblich, Hans Koster, Miren Lafourcade, Kristoffer Möller, Ismir Mulalic, Jos van Ommeren, Henry Overman, Michael Pflüger, Rosa Sanchis-Guarner, Simone Schüller, Sevrin Waights and Yanos Zylberberg for helpful comments and suggestions. Kristoffer Möller and Sevrin Waights provided outstanding help with the compilation of the data set. Sascha Möbius and Neele Reimann-Phillip also provided excellent research assistance. We thank the Berlin Committee of Valuation Experts and the Senate Department for Urban Development and the Environment for providing property transaction data. The German Science Foundation (DFG project code NI 938/2-1) and the FritzThyssen-Foundation (project code AZ.10.10.2.070) are acknowledged for financial support. The usual disclaimers apply. 